\title{
Spatial characteristics of bicycle-motor vehicle crashes in Christchurch, New Zealand: A case-control approach
}

\author{
Tom Williams \\ Lincoln University \\ Tom.williams2@lincolnuni.ac.nz \\ Shannon Page \\ Lincoln University
}

\author{
Crile Doscher \\ Lincoln University
}

\begin{abstract}
This paper aims to examine the risk of bicycle-motor vehicle crashes occurring on a network-wide level in Christchurch, New Zealand, based on the spatial characteristics present in the road environment. To achieve this, logistic regression was undertaken with a binary dependent variable (crash/non-crash) using a case-control strategy, with case sites being locations of reported crashes, while control sites were sampled from the road network in proportion to where people cycle. Due to the uncertainty of cycling flows in Christchurch, four logistic regression models were undertaken based on different route selection preferences.

The results identified that the odds of a crash increased across all four models due to the presence of driveways or intersections, identifying that these characteristics are associated with an increase in crash risk. All of the models identified that the risk of a crash decreases with the presence of on-road cycle lanes, while crash risk due to the presence of specific planning zones or road classification varied across all of the models.
\end{abstract}

\section{Article history:}

Received: February 26, 2017

Received in revised form:

November 7, 2017

Accepted: March 14, 2018

Available online: October 22,

2018

Data availability: jtlu.org/index.

$\mathrm{php/jtlu/article/view/1147}$

\section{$1 \quad$ Introduction}

As a form of transportation, the use of the bicycle has numerous individual and societal benefits. These include increased transport efficiency (City of Copenhagen, 2009; Vandenbulcke et al., 2011), numerous health benefits due to an increase in physical activity (Rietveld \& Daniel, 2004; City of Copenhagen, 2009; Rabl \& de Nazelle, 2012) and environmental benefits associated with a reduction in the use of fossil fuels (Rietveld \& Daniel, 2004; City of Copenhagen, 2009; Nielsen, Olafsson, Carstensen, \& Skov-Petersen, 2013). Despite these benefits, the use of the bicycle as a mode of transport remains low in many countries around the world when compared to other transport modes.

One of the main barriers in achieving a modal shift from the private motor vehicle to the bicycle

Copyright 2018 Tom Williams, Crile Doscher \& Shannon Page

http://dx.doi.org/10.5198/jtlu.2018.1147

ISSN: 1938-7849 | Licensed under the Creative Commons Attribution - Noncommercial License 4.0

The Journal of Transport and Land Use is the official journal of the World Society for Transport and Land Use (WSTLUR) and is published and sponsored by the University of Minnesota Center for Transportation Studies. 
relates to how safe cycling is perceived to be compared to other transport modes. Evidence suggests a link between participation levels in cycling and cycling safety, as negative perceptions surrounding safety have a significant impact on the number of people who choose to cycle (Cycling Safety Panel, 2014). As cycling in New Zealand is more dangerous than driving a car, with bicycle users being involved in 7\% of crashes while only accounting for $1 \%$ of the transport mode share (Ministry of Transport [MOT], 2014), the issue of bicycle safety needs to be addressed to encourage more people to cycle.

The intention of this paper is: (1) to contribute to the progression of bicycle safety research by analyzing how specific characteristics of the road and built environments influence the likelihood of a crash occurring, and (2) to develop an approach to identify high risk areas for bicycle crashes in Christchurch. The analysis undertaken in this study was based on a crash report database which contains reports of crashes between motor vehicles and bicycles completed by the police at the time of the crash. Using a case-control study approach, a multiple logistic regression model was developed to identify the common characteristics of bicycle-motor vehicle crashes.

The layout of this paper is as follows: Section 2 provides a literature review of both the factors that contribute to bicycle crashes, along with current research practices in the field of bicycle crash research. Section 3 introduces the Christchurch case study and outlines the methods and data used to conduct this research. Section 4 provides the results of the regression analysis undertaken, while section 5 provides more in-depth analysis of these results.

\section{$2 \quad$ Literature review}

The use of cycling as a form of transportation varies around the world with European countries such as the Netherlands, Germany and Denmark having high modal shares of between 10\% and 27\% (Pucher \& Buehler, 2008) compared to Australia, New Zealand and the United States where cycling accounts for approximately $1 \%$ of the transport mode share (Pucher \& Buehler, 2008; MOT, 2014). Suggestions for this high variation in modal share included differences in urban form (Frumkin, Frank \& Jackson, 2004) and the perceived and actual crash risk associated with cycling (Reynolds, Harris, Teschke, Cripton, \& Winters, 2009; Cycling Safety Panel 2014).

With regards to urban form, Wiersma, Bertolini \& Straatemeier (2016) identify that bicycle use is highest in cities with distinct urban boundaries, while the opposite is also true with low levels of bicycle use being associated with areas of urban sprawl (Ewing, Meakins, Hamidi, \& Nelson, 2014). On a neighborhood scale, the completion of bicycle infrastructure at the same time as mixed use developments can be associated with a higher cycling modal share than in surrounding areas (Bertolini \& le Clercq, 2003). Moreover, mixed use developments are also associated with lower levels of traffic congestion when compared to suburban corridors due to shorter trip distances and a higher non-motorized mode share (Kuzmyak, 2012).

As the risk of being involved in a crash increases with the number of motorists but decreases with the number of pedestrians or cyclists (Räsänen \& Summala, 1998; Jacobsen, 2003), it is likely that as the number of people cycling increases, the injury rate will decrease due to a "safety in numbers effect" (Jacobsen, 2003; Elvik, 2008) as motorists are likely to adjust their driving habits with an increase in bicycle users (Jacobsen, 2003). On the other hand, as motorists and bicycle users are not used to sharing the road they may hold incorrect assumptions about what the other party is likely to do and making "look but failed to see errors" (Herslund \& Jorgensen, 2003).

In undertaking a review of literature relating to the impact of transport infrastructure on cyclist injuries, Reynolds et al., (2009) suggest that there is a relationship between transport infrastructure and cyclist crash and injury risk. Schepers, Hagenzieker, Methorst, van Wee, and Wegman (2013a) state that 
the likelihood of being involved in a crash is the result of the interaction between road user(s), vehicle(s) and infrastructure. Furthermore, the likelihood of a crash occurring depends on the number of conflict points present in a road segment, coupled with how well road users deal with these conflicts (Schepers, Heinen, Methorst, \& Wegman, 2013b).

With regards to infrastructure type, crash risk increases with the presence of driveways (Chimba, Emaasit, \& Kutela, 2012), high traffic speeds (Kim, Kim, Ulfarsson, \& Porrello, 2007), intersections (Isaksson-Hellman, 2012) and specific road classifications (Li, Zhu, \& Sui, 2007) while the presence of bicycle-only infrastructure (e.g., separated cycling facilities, cycle routes and bike lanes) reduces the crash risk compared to mixing with traffic (Reynolds et al., 2009). Of particular interest, in New Zealand and North America, the presence of marked on road cycle lanes has been associated with a crash risk reduction (Parsons \& Koorey, 2013; Reynolds et al., 2009) while on a world-wide scale Stewart and McHale (2014) suggest that there is much contradictory evidence surrounding the benefits of cycle lanes.

Reynolds et al. (2009) identify that there are significant gaps present in the literature as the majority of research available which focused on intersections is of a European context and primarily focused on roundabouts, while the majority of research focused on mid-block facilities (e.g., the use of cycle lanes) is from a North American perspective. Moreover, other limiting factors in crash research include the difficulty in being able to control for the exposure to crash risk (Reynolds et al., 2009) and the difficulty in obtaining adequate information on the independent variables present (Wallentin \& Loidl, 2015).

Vandenbulcke, Thomas and Int Panis (2014) suggest research investigating collision risk can generally be classified as using one of three modelling approaches; crash-frequency models, crash-collision models and crash-severity models. An issue with crash-frequency and severity models is that they can lead to the inaccurate distribution of crash frequency information (Lord \& Mannering, 2010). One way to overcome this is through the use of a case-control methodology (such as in Vandenbulcke et al., 2014; Teschke et al., 2012). Case-control studies have their origins in epidemiological and ecological research where controls are utilized in presence-absence studies (Vandenbulcke et al., 2014). In such studies case events are locations where crashes have been observed as occurring while controls are locations where crashes could occur in proportion to where people cycle (Vandenbulcke et al., 2014). Grimes and Schulz (2005) suggest that the use of controls are beneficial as they are able to estimate the frequency of an exposure in the population under study.

The limitations of case-control studies relate to the selection of case events and a lack of information surrounding bicycle users' exposure to the outcome of interest (e.g., crashes) (Organization for Economic Co-operation and Development, 2013; Vandenbulcke et al., 2014; Loidl, Wallentin, Wendel, \& Zagel, 2016). The selection of case events is commonly derived from the use of traffic crash reports or hospital records to identify the locations where crashes were reported as occurring (e.g., Teschke et al., 2012; Hels \& Orozova-Bekkevold, 2007; Kim et al., 2007; Bíl, Bílová, \& Müller, 2010). However, as the under-reporting of bicycle crashes (particularly minor ones) is a well-documented weakness of official crash reports (de Geus et al., 2012; Wegman, Zhang, \& Dijkstra, 2012; Aertsens et al., 2010; Loo \& Tsui ,2010; Parkin \& Meyers, 2007; Aultman-Hall \& Kaltenecker, 1999) it is likely that research findings based on such reports may not generally apply to all crashes (Teschke et al., 2012). Along with the under-reporting of bicycle crashes, Loo and Tsui (2010) identify that it is often necessary to aggregate the crash data over a number of years to improve the statistical reliability of the study as crashes involving motor vehicles and bicycles are relatively rare events. However, Eckhardt and Thomas, (2005) warn that doing so may lead to data generalization and the loss of information on a local scale, leading to unreliable model results. Loidl et al., (2016) identify that one way to determine the robustness of the risk calculation models is through the use of $95 \%$ confidence intervals, with the size of the intervals 
determining the robustness of the model (with larger confidence intervals identifying a lower level of statistical robustness).

A factor limiting the development of case-control studies relates to the limited information available surrounding the exposure to risk (Reynolds et al., 2009), with the information that is available typically consisting of census data, household travel surveys and travel diaries (de Geus et al., 2012). This information is then required to be developed further in order to gain a more in-depth understanding of cycling flows on a network-wide level (Loidl et al., 2016). This development can be achieved either through the use of gravity-based models (Vandenbulcke et al., 2014), or more recently, the use of transport models (see Wallentin \& Loidl, 2016; Roberts, 2014; Transport for London, 2017; Ziemeke, Metzler, \& Nagel, 2017).

The use of regression analysis for the development of crash frequency and severity models is widespread among the literature surrounding bicycle crashes. Regression analysis attempts to explain how well the independent variables (the characteristics of interest) explain the dependent variable (whether a crash occurred). The resulting coefficients (and odds ratios) of this model indicate the significance of each independent variable at being able to explain the dependent variable. The development of regression analysis methods and their applicability to this study can be seen through the examination of previous studies undertaken by Wang and Nihan (2004), Schepers, Kroeze, Sweers and Wüst (2011) and Vandenbulcke et al., (2014). As the purpose of the study by Wang and Nihan (2004) was to determine bicycle crash risk at a specific set of intersections based on bicycle and vehicle flow rates, negative binominal regression was undertaken as the dependent variable (number of crashes) was in the form of count data. Similarly, to this, the study undertaken by Schepers et al., (2011) also undertook negative binominal regression, however the number of independent variables was increased to eight.

\section{$3 \quad$ Methods}

The analyses described in this paper was conducted in Christchurch, the second largest city in New Zealand, with a population of approximately 350,000 people (Statistics New Zealand, 2013). Despite the flat topography, mild climate and relative compact size of the city (the majority of residential suburbs are within $6 \mathrm{~km}$ of the city center), cycling only accounted for $5 \%$ of the journey to work mode share in 2013 (Statistics New Zealand, 2013). At the time of this study, the transport network in Christchurch consisted of 2,000 kilometers of roads, 65 kilometers of painted on-road cycle lanes and 25 kilometers of separated shared use paths. Cycle lanes in Christchurch must be a minimum width of $1.6 \mathrm{~m}$ (Christchurch City Council [CCC], 2016), therefore only sections of cycle lanes which were $1.6 \mathrm{~m}$ or wider were included in this study.

\subsection{Study overview}

As the intention of this research was to identify how specific infrastructure characteristics contribute to an increase in crash probability, a case-control study was used as it allows for the creation of a dichotomous dependent variable against which the presence/absence of specific characteristics can be measured. The dichotomous dependent variable for this research is the location of crashes/non-crashes that occurred in Christchurch. The case events are those crashes that occurred between 2003 and 2009, and are based on police reports compiled at the time of occurrence. These reports contain the GPS coordinates of the crash, injury severity and spatial characteristics (such as the presence of driveways or if the crash occurred at an intersection). This information is collated by the New Zealand Transport Agency and stored in the Crash Analysis System (CAS) database. To ensure statistical robustness, Grimes and Schulz 
(2005) suggest that the ratio of controls to cases should be 4:1. As there were 785 reported crashes in the CAS database for the study time period, 3140 controls were randomly placed along the cycling routes identified between predefined zones of the Christchurch Strategic Cycle Model (SCM).

\subsection{Origin and destination locations}

To enable the network models to be built, a number of origin and destination points were created within each SCM zone (Figure 1) using a random lookup function on an address geocoder; the number of points created within each zone was based on the number of inter and intra zonal trips which started or ended within each SCM zone.

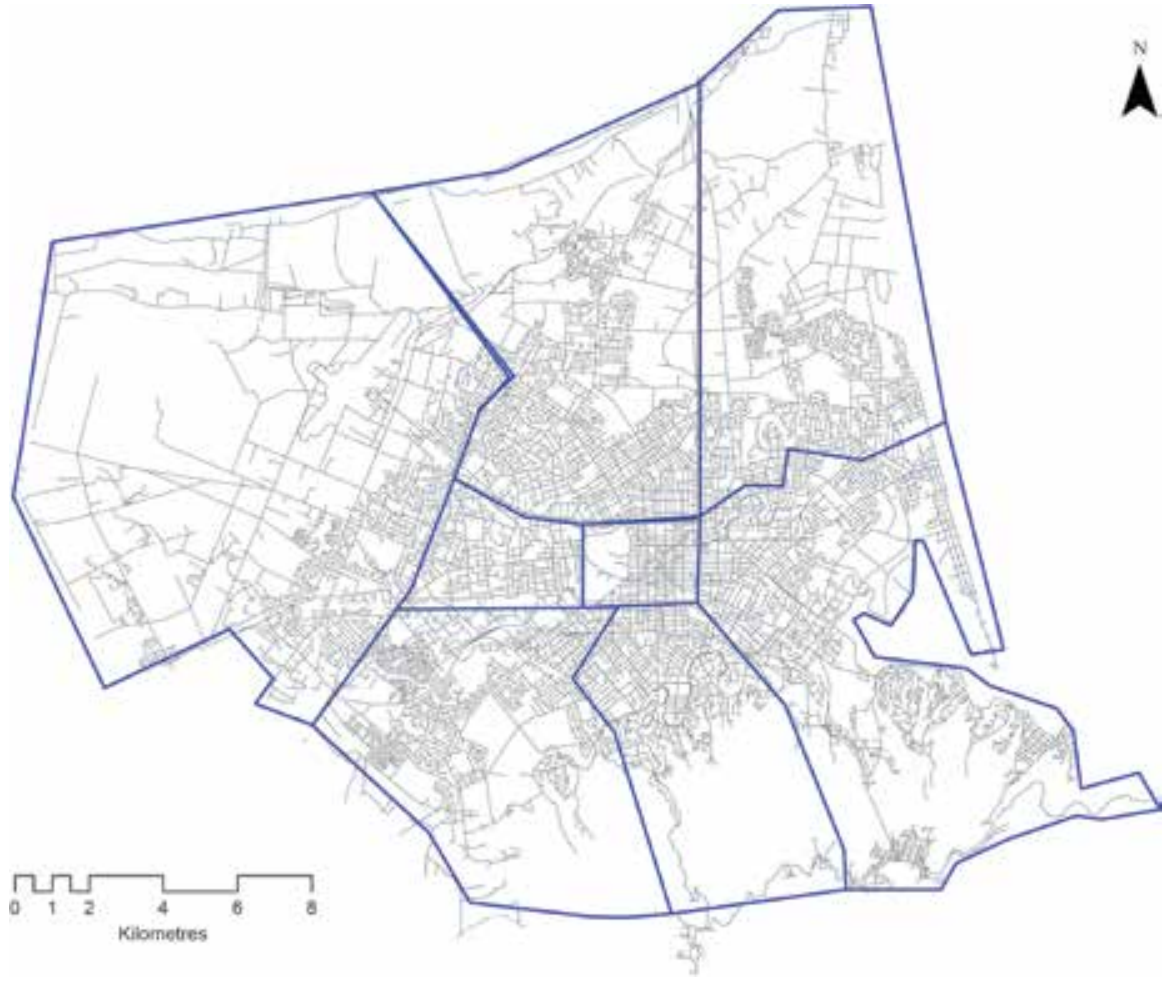

Figure 1: Study context and SCM zones

The SCM was used to understand where people cycle for both home based and non-home based trip purposes (for work, education and other trips). Within the SCM cycling flows are identified based on census travel mode share, household travel surveys and the land use characteristics of each zone (Roberts, 2012). As the decision of where to cycle is complex when compared to motorized transport (Koh \& Wong, 2013), it was also necessary to define these route preferences before route assignment was determined. The 3140 controls for each zone were placed in proportion to the number of people cycling along these routes for each model based on the SCM.

\subsection{The network model(s)}

Cycling route preferences were informed using the identification by Dill and McNeil (2014) that a small segment of a cycling population typically chooses to cycle no matter what the conditions are, with around $10 \%$ of people preferring to find a balance between the direct nature of the cycle route and the amount of cycling infrastructure available. In contrast to this, the majority of a population (up to 60\%) will only cycle in low traffic speed/volume environments or where there is physical separation between 
bicycles and motor vehicles (Dill \& McNeil, 2014).

\subsection{Model creation}

Based on the route choice preferences identified in table 1, multiple network models were built using Model Builder in ArcMap 10.3 to allow multiple route analysis options to be undertaken. In total, four different route models between each SCM zone were generated.

Table 1: Model number and route preference

\begin{tabular}{|l|l|}
\hline Model & Route preference \\
\hline 1 & Use routes with the highest amount of cycle facilities \\
\hline 2 & Use only low traffic streets (traffic volume below 10,000 vehicles per day) \\
\hline 3 & Most direct (shortest distance) \\
\hline 4 & Quickest (shortest amount of time) \\
\hline
\end{tabular}

Before the analysis was undertaken a Network dataset was created which contained the following analysis layers; road segments with cycle lanes, cycle paths and intersection locations, along with an address lookup feature to create the origin and destination locations (these were random point locations placed in each SCM zone to reflect the number of bicycle trips that occurred either within each zone or where the origin/destination was in a respective zone).

To run the analysis based on each of the route preferences, the impedance function of Network Analyst was set to either length (for the model representing the most direct route) or for travel time for all other route choices. The length impedance was calculated using the length field associated with each of the analysis layers, while the travel time impedance was calculated by dividing the length by the bicycle speed field (this was set to $25 \mathrm{~km} / \mathrm{h}$ for separated bicycle infrastructure and $18 \mathrm{~km} / \mathrm{h}$ for road segments as cycling on separated infrastructure is often associated with faster cycling trips due to intersection priority and fewer conflict points) and then converted to minutes. To ensure that the routes created based on models 1-2 (identified in table 1) reflected the users' intentions, the restriction functions associated with each of the analysis layers were manipulated by setting the preferred facility type to prefer: high and the preferences for all other facility types to either prefer: low or avoid.

\subsection{Placement of controls}

To maintain a ratio of 4:1 ratio of controls to cases, 3140 controls were placed along the routes created within each model. Control placement was undertaken using a random number generator in order to randomly generate and place the specified number of controls along the respective routes between each of the SCM zones in proportion to the cycling flows between each zone.

\subsection{Data extraction and analysis}

Police crash reports and previous research identified a number of variables that are likely to contribute to the risk of a crash between a bicycle and motor vehicle occurring. To identify if these characteristics were present at the case and control sites, the analysis layers described in table 2 were created. 
Table 2: Variables included in the analysis

\begin{tabular}{|c|c|c|}
\hline Variable name & Categories & Data source \\
\hline Dependent variable: Case/control & Case Control & Case: CAS crash data base \\
\hline $\begin{array}{l}\text { Cycle lanes (locations were cycle lanes } \\
\text { were located on both sides of the road }{ }^{1}\end{array}$ & $\begin{array}{l}\text { Cycle lane } \\
\text { No cycle lane }\end{array}$ & $\begin{array}{l}\text { Based on Christchurch City Council cycling map } \\
\text { (2008). }\end{array}$ \\
\hline $\begin{array}{l}\text { Cycle paths (physically separated from } \\
\text { motorized traffic). }\end{array}$ & $\begin{array}{l}\text { 1: Cycle path } \\
0: \text { No cycle path }\end{array}$ & $\begin{array}{l}\text { Based on Christchurch City Council cycling map } \\
\text { (2008) }\end{array}$ \\
\hline Driveways & $\begin{array}{l}\text { 1: Driveway present } \\
0 \text { : Driveway absent }\end{array}$ & $\begin{array}{l}\text { Case: CAS crash database } \\
\text { For the case locations, whether or not the crash } \\
\text { occurred in a driveway was obtained from the police } \\
\text { crash data.) } \\
\text { Control: Based on NZ Street address points (Land } \\
\text { Information New Zealand, 2011). } \\
\text { For the control points (which were randomly placed } \\
\text { on the road network in proportion to cycling flows) } \\
\text { the driveways dataset was created based on the street } \\
\text { address point layer. }\end{array}$ \\
\hline Intersections & $\begin{array}{l}\text { 1: Intersection } \\
0: \text { No intersection }\end{array}$ & $\begin{array}{l}\text { Case: CAS database (New Zealand Transport Agency, } \\
2014 a \text { ). } \\
\text { For case locations, police reports were required to } \\
\text { identify whether or not collisions occurred within } \\
10 \mathrm{~m} \text { of an intersection. (New Zealand Transport } \\
\text { Agency, 2014b). } \\
\text { Controls: Christchurch City Council intersection } \\
\text { dataset (n.d.) } \\
\text { Control locations were treated in the same manner } \\
\text { by creating a } 10 \mathrm{~m} \text { buffer around the central point of } \\
\text { an intersection. }\end{array}$ \\
\hline $\begin{array}{l}\text { Road classification } \\
\text { Refers to the function of the road in } \\
\text { the overall transport network. }\end{array}$ & $\begin{array}{l}\text { Reference: Collector road } \\
\text { Private road } \\
\text { Local road } \\
\text { Minor Arterial } \\
\text { Major Arterial }\end{array}$ & Christchurch City Council (2012). \\
\hline Speed limit & $\begin{array}{l}\text { Reference: } 30 \mathrm{~km} / \mathrm{h} \\
50 \mathrm{~km} / \mathrm{h} \\
60 \mathrm{~km} / \mathrm{h} \\
70 \mathrm{~km} / \mathrm{h} \\
80 \mathrm{~km} / \mathrm{h} \\
100 \mathrm{~km} / \mathrm{h}\end{array}$ & Christchurch City Council (2011). \\
\hline $\begin{array}{l}\text { Planning Zone (Planning zones set } \\
\text { out what type of activities are allowed } \\
\text { to happen in each area. For example, } \\
\text { housing is only permitted in residential } \\
\text { zones while open space zones are for } \\
\text { open land such as parks). }\end{array}$ & $\begin{array}{l}\text { Reference: Business } \\
\text { 1: Conservation (heritage) } \\
\text { 2: Cultural } \\
\text { 3: Open Space } \\
\text { 4: Residential } \\
\text { 5: Rural } \\
\text { 6: Special Purpose Zone }\end{array}$ & Christchurch City Council (2016). \\
\hline
\end{tabular}

${ }^{1}$ Under the Christchurch City Council operational guidelines cycle lanes must be a minimum of $1.6 \mathrm{~m}$ wide.

${ }^{2}$ To create the driveway point layer, odd and even addresses were separated and assigned to separate sides of the line segment and buffered to a diameter of $3 \mathrm{~m}$.

${ }^{3}$ For intersections, if a case/control fell on an approach where a cycle lane or cycle path was present it would be identified as occurring on a route segment where a cycle lane or cycle path was present. 
Next, a spatial join was performed to populate the control dataset with information regarding the independent variables. This dataset was then merged with the case dataset to create the analysis layers for each model. This was then exported from ArcGIS and binomial logistic regression undertaken using SPSS.

\section{The inclusion of cycle paths}

Although by default crashes cannot occur on cycle paths as motor vehicles are excluded on these facilities, they were included in the network models (and the placement of controls) as cycle paths represent locations where people are able to cycle. In addition to this, the inclusion of the cycle path variable in the regression models played a part in the calibration of these models. If the cycle path variable was identified as being significant then the model would be wrong.

\section{$4 \quad$ Results}

Table 3 below contains the descriptive characteristics and the $\mathrm{R}^{2}$ for each of the four models. The $\mathrm{R}^{2}$ identified that model 3 explains the highest amount of variance in the dependent variable (cases/ controls) while model 1 explains the least.

Table 3: Descriptive characteristics of the four models

\begin{tabular}{|c|c|c|c|c|c|}
\hline & \multicolumn{4}{|c|}{ Model } \\
\hline & & 1 & 2 & 3 & 4 \\
\hline Nagelkerke R2 & & 0.31 & 0.58 & 0.62 & 0.51 \\
\hline Variable & Percentage of cases & \multicolumn{4}{|c|}{ Percentage of controls } \\
\hline \multicolumn{6}{|l|}{ Cycle lane } \\
\hline Absent & $61 \%$ & $18 \%$ & $19 \%$ & $13 \%$ & $16 \%$ \\
\hline Present & $39 \%$ & $82 \%$ & $81 \%$ & $87 \%$ & $84 \%$ \\
\hline \multicolumn{6}{|l|}{ Cycle Path } \\
\hline Present & $0 \%$ & $5 \%$ & $6 \%$ & $4 \%$ & $4 \%$ \\
\hline Absent & $100 \%$ & $95 \%$ & $94 \%$ & $96 \%$ & $96 \%$ \\
\hline \multicolumn{6}{|l|}{ Driveway } \\
\hline Present & $70 \%$ & $24 \%$ & $23 \%$ & $24 \%$ & $17 \%$ \\
\hline Absent & $30 \%$ & $76 \%$ & $77 \%$ & $76 \%$ & $83 \%$ \\
\hline \multicolumn{6}{|l|}{ Intersection } \\
\hline Present & $43 \%$ & $51 \%$ & $52 \%$ & $48 \%$ & $49 \%$ \\
\hline Absent & $57 \%$ & $49 \%$ & $48 \%$ & $52 \%$ & $51 \%$ \\
\hline \multicolumn{6}{|l|}{ Speed Limit } \\
\hline $30 \mathrm{~km} / \mathrm{h}$ & $1 \%$ & $4 \%$ & $2 \%$ & $2 \%$ & $2 \%$ \\
\hline $40 \mathrm{~km} / \mathrm{h}$ & $1 \%$ & $1 \%$ & $1 \%$ & $1 \%$ & $1 \%$ \\
\hline $50 \mathrm{~km} / \mathrm{h}$ & $87 \%$ & $86 \%$ & $87 \%$ & $85 \%$ & $88 \%$ \\
\hline $60 \mathrm{~km} / \mathrm{h}$ & $6 \%$ & $4 \%$ & $5 \%$ & $5 \%$ & $6 \%$ \\
\hline $70 \mathrm{~km} / \mathrm{h}$ & $2 \%$ & $3 \%$ & $2 \%$ & $4 \%$ & $1 \%$ \\
\hline
\end{tabular}


Table 3: Descriptive characteristics of the four models (cont.)

\begin{tabular}{|c|c|c|c|c|c|}
\hline & \multicolumn{4}{|c|}{ Model } \\
\hline & & 1 & 2 & 3 & 4 \\
\hline \multirow{2}{*}{$\begin{array}{l}\text { Nagelkerke R2 } \\
\text { Variable }\end{array}$} & \multirow[b]{2}{*}{ Percentage of cases } & 0.31 & 0.58 & 0.62 & 0.51 \\
\hline & & \multicolumn{4}{|c|}{ Percentage of controls } \\
\hline $80 \mathrm{~km} / \mathrm{h}$ & $3 \%$ & $2 \%$ & $3 \%$ & $3 \%$ & $2 \%$ \\
\hline \multicolumn{6}{|l|}{ Road Class } \\
\hline Collector Road & $20 \%$ & $14 \%$ & $13 \%$ & $16 \%$ & $15 \%$ \\
\hline Local Road & $23 \%$ & $55 \%$ & $53 \%$ & $60 \%$ & $61 \%$ \\
\hline Major Arterial & $10 \%$ & $8 \%$ & $9 \%$ & $5 \%$ & $4 \%$ \\
\hline Minor Arterial & $47 \%$ & $15 \%$ & $15 \%$ & $11 \%$ & $12 \%$ \\
\hline Pedestrian & $0 \%$ & $5 \%$ & $6 \%$ & $4 \%$ & $4 \%$ \\
\hline Private & $0 \%$ & $4 \%$ & $4 \%$ & $4 \%$ & $5 \%$ \\
\hline \multicolumn{6}{|l|}{ Planning Zone } \\
\hline Business Zone & $23 \%$ & $14 \%$ & $13 \%$ & $14 \%$ & $14 \%$ \\
\hline Conservation zone & $2 \%$ & $3 \%$ & $2 \%$ & $2 \%$ & $2 \%$ \\
\hline Cultural Zone & $0 \%$ & $0 \%$ & $0 \%$ & $1 \%$ & $1 \%$ \\
\hline Open Space Zone & $1 \%$ & $1 \%$ & $2 \%$ & $2 \%$ & $2 \%$ \\
\hline Residential Zone & $70 \%$ & $79 \%$ & $78 \%$ & $79 \%$ & $78 \%$ \\
\hline Rural Zone & $4 \%$ & $2 \%$ & $2 \%$ & $1 \%$ & $2 \%$ \\
\hline Special Purpose Zone & $1 \%$ & $1 \%$ & $2 \%$ & $1 \%$ & $1 \%$ \\
\hline
\end{tabular}

Table 4 presents the results of the four logistic models showing those characteristics which are identified as being significant $(\mathrm{p}<0.05)$ in explaining where crashes between motor vehicles and cyclists occur. An odds ratio (OR) of greater than 1 identifies that a variable increases the odds of a crash occurring, while an odds ratio of less than 1 identifies that a variable decreases the odds of a crash occurring by that factor.

Driveways, intersections and cycle lanes are statistically significant across all four models while the significance of other variables varies across each of the models. 
Table 4: Comparison of the four models and infrastructure characteristics

\begin{tabular}{|c|c|c|c|c|c|c|c|c|c|c|c|c|}
\hline & \multicolumn{3}{|c|}{ Model 1} & \multicolumn{3}{|c|}{ Model 2} & \multicolumn{3}{|c|}{ Model 3} & \multicolumn{3}{|c|}{ Model 4} \\
\hline & \multirow{2}{*}{ OR } & \multicolumn{2}{|c|}{ 95\% C.I.for OR } & \multirow{2}{*}{ OR } & \multicolumn{2}{|c|}{ 95\% C.I.for OR } & \multirow{2}{*}{ OR } & \multicolumn{2}{|c|}{ 95\% C.I.for OR } & \multirow{2}{*}{ OR } & \multicolumn{2}{|c|}{$95 \%$ C.I.for OR } \\
\hline & & Lower & Upper & & Lower & Upper & & Lower & Upper & & Lower & Upper \\
\hline Cycle lane & 0.57 & 0.43 & 0.75 & 0.44 & 0.33 & 0.59 & 0.33 & 0.26 & 0.43 & 0.29 & 0.22 & 0.39 \\
\hline Cycle Path & \multicolumn{3}{|c|}{ Not significant } & \multicolumn{3}{|c|}{ Not significant } & \multicolumn{3}{|c|}{ Not significant } & \multicolumn{3}{|c|}{ Not significant } \\
\hline Driveway & 31.67 & 24.78 & 40.47 & 31.13 & 23.98 & 40.41 & 7.07 & 5.84 & 8.57 & 29.94 & 23.08 & 38.84 \\
\hline Intersection & 1.31 & 1.07 & 1.61 & 1.47 & 1.21 & 1.79 & 1.47 & 1.21 & 1.79 & 1.58 & 1.28 & 1.95 \\
\hline Speed Limit & \multicolumn{3}{|c|}{ Not significant } & \multicolumn{3}{|c|}{ Not significant } & \multicolumn{3}{|c|}{ Not significant } & \multicolumn{3}{|c|}{ Not significant } \\
\hline \multicolumn{13}{|l|}{ Road Class } \\
\hline Collector & \multicolumn{3}{|c|}{ Reference category } & \multicolumn{3}{|c|}{ Reference category } & \multicolumn{3}{|c|}{ Reference category } & \multicolumn{3}{|c|}{ Reference category } \\
\hline Local Road & 0.38 & 0.28 & 0.51 & 0.43 & 0.32 & 0.59 & 0.59 & 0.45 & 0.77 & 0.45 & 0.33 & 0.61 \\
\hline $\begin{array}{l}\text { Major } \\
\text { Arterial }\end{array}$ & 0.34 & 0.21 & 0.55 & 0.30 & 0.18 & 0.52 & 0.31 & 0.19 & 0.50 & 0.40 & 0.23 & 0.70 \\
\hline $\begin{array}{l}\text { Minor } \\
\text { Arterial }\end{array}$ & \multicolumn{3}{|c|}{ Not significant } & 1.48 & 1.05 & 2.07 & \multicolumn{3}{|c|}{ Not significant } & 1.75 & 1.24 & 2.46 \\
\hline Private & \multicolumn{3}{|c|}{ Not significant } & 0.06 & 0.01 & 0.24 & 0.08 & 0.02 & 0.04 & 0.05 & 0.01 & 0.21 \\
\hline Pedestrian & 0.04 & 0.01 & 0.17 & \multicolumn{3}{|c|}{ Not significant } & \multicolumn{3}{|c|}{ Not significant } & \multicolumn{3}{|c|}{ Not significant } \\
\hline $\begin{array}{l}\text { Planning } \\
\text { Zone }\end{array}$ & & & & & & & & & & & & \\
\hline Business Zone & & erence cat & & & erence cat & & & Erence cat & & & ference cat & \\
\hline $\begin{array}{l}\text { Conservation } \\
\text { Zone }\end{array}$ & & ot signifu & & & Vot signific & & & ot signific & & & Iot signific & \\
\hline Cultural Zone & & ot signifi & & & ot signific & & & ot signifi & & & Vot signifu & \\
\hline $\begin{array}{l}\text { Open Space } \\
\text { Zone }\end{array}$ & 0.35 & 0.10 & 1.19 & 0.33 & 0.10 & 1.12 & 0.27 & 0.09 & 0.77 & & Iot signific & \\
\hline $\begin{array}{l}\text { Residential } \\
\text { Zone }\end{array}$ & 0.48 & 0.36 & 0.62 & 0.49 & 0.37 & 0.65 & 0.54 & 0.42 & 0.69 & 0.61 & 0.46 & 0.81 \\
\hline Rural Zone & & ot signifu & & & Iot signific & & & ot signifi & & & Not signific & \\
\hline $\begin{array}{l}\text { Special } \\
\text { Purpose Zone }\end{array}$ & & Iot signifu & & 0.39 & 0.15 & 1.02 & 0.23 & 0.10 & 0.55 & & Iot signific & \\
\hline Constant & 0.07 & & & 0.06 & & & 0.21 & & & 0.11 & & \\
\hline
\end{tabular}

${ }^{A B}$ For variables with multiple categories, the logistic model compares these categories against a default or dummy variable, these were ${ }^{\mathrm{A}}$ Collector roads and, ${ }^{\mathrm{B}}$ Business planning zones.

\section{Discussion}

All four models identified that intersections and driveways contribute to an increase in crash odds reflecting the findings of previous studies undertaken by Isaksson-Hellman, (2012) for intersections and Chimba et al., (2012) for driveways. Regarding intersections, the findings of this research reflects the findings of previous studies which are of European context (Reynolds et al., 2009).

This study has also identified that cycle lanes are associated with a decrease in crash odds, reflecting the findings of Parsons and Koorey, (2013) and Reynolds et al., (2009). However, as the majority of people prefer to cycle on routes with either physically separated infrastructure or low traffic volumes and speeds (Dill \& McNeil, 2014), it is likely that the benefit provided by on-road cycle lanes is limited as they remain an unattractive option for the majority of people, therefore preventing the safety in numbers effect (Jacobsen, 2003; Elvik, 2008) from occurring. 
In comparison to collector roads, crash odds decreased across all models on either local roads or major arterial roads, reflecting similar findings to Schepers et al., (2011) who identified that crash risk increases on collector/distributor roads when compared to local roads. The indication that major arterial routes decreased crash risk while minor arterials elevated crash risk may be due to increased traffic congestion levels on major arterials during peak travel periods resulting in lower traffic speeds.

Residential and open space planning zones were associated with a decrease in crash odds across all models, while special purpose zones were associated with a reduction across models 2 , and 3 when compared to business planning zones. As business zones are areas of commercial activity, it is likely that the flow-on effects of these activities result in a more complex road environment (e.g., higher concentrations of on street parking, more vehicles entering and exiting driveways and a busier road environment) when compared to other zone types. It is likely that it is this more complex road environment that increases crash risk in business zones.

Figure 2 represents changes of crash risk for a section of the road network in Christchurch. It provides decision makers with a tool to clearly identify sections of the road network where bicycle-motor vehicle crash risk has increased due to the presence of specific spatial characteristics. This figure represents the combined odds ratio of the independent variables identified as being significant in model 3 .

In interpreting figure 2, it is important to note that the figure represents a change in crash risk due to the presence/absence of specific spatial characteristics and does not identify the net crash risk associated with cycling on a specific road segment. Moreover, the changes in risk displayed are of a dynamic nature as they are reflective of current cycling patterns, as the road and cycle networks develop so will this risk due to a change in travel behavior and surrounding land use.

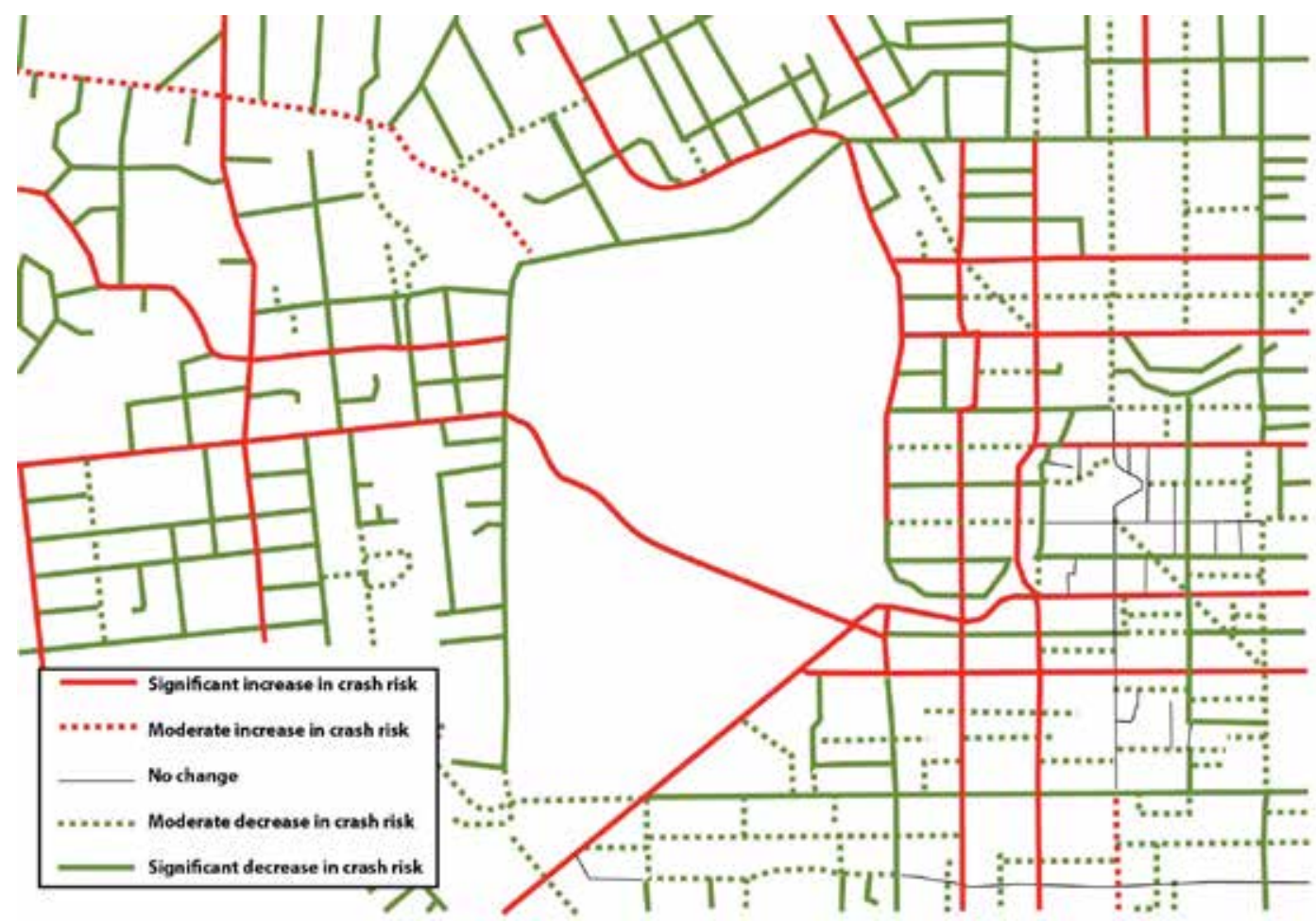

Figure 2: Changes in bicycle-motor vehicle crash probability for a portion of Christchurch due to spatial characteristics present in the road environment 


\subsection{Strength and limitations}

A strength of this study is that it has identified characteristics present in the road environment that contribute to explaining the locations of where bicycle-motor vehicle crashes occur in proportion to where people cycle. This is the first large scale case-control study that the authors are aware of that has occurred outside of the European context.

The fact that this study has utilized a cycling flow model identifies that the use of such models is suited to the purpose of generating exposure information, reducing the complexity and time required to undertake large scale case-control studies. Furthermore, as the network models used to generate the control sites have not been validated against actual use, the calculated odds ratios may not reflect current conditions though incorporating data from SCM zones has reduced this effect.

As this study utilized police crash reports, the findings of this research are not likely to reflect all crashes that occur between bicycles and motor vehicles but instead those crashes which are reported to the police (and predominantly result in serious and fatal injuries).

Finally, the independent variables included in the analysis were limited by the information available and did not cover the wide range of infrastructure types present in urban road environments.

\section{Conclusion}

Despite there being large variations in cycling modal share on a global scale, most countries are seeing the use of the bicycle as a form of transportation rapidly increasing as more people become aware of the benefits associated with bicycle use. Despite this, significant gaps still remain in research surrounding bicycle use and in particular how bicycle-motor vehicle crash probability is influenced by the surrounding spatial characteristics. The intention of this study was to build on previous research undertaken in a European context to identify if these findings were applicable to the Australasian context by identifying how specific spatial characteristics present in the road environment in Christchurch, New Zealand contribute to either an increase or decrease in crash risk.

The chosen method for this research (a case-control study through the use of logistic regression) is a developing field in bicycle crash research, particularly when investigating bicycle use on a network-wide level. This is due to a significant obstacle in undertaking this type of research being a lack of reliable exposure data identifying where people choose to cycle in a network-wide context.

As relatively little is known about where people choose to cycle, this research developed four route scenarios to determine how crash risk due to specific road characteristics changes based on where people choose to cycle.

The results of these models identified that the presence of driveways, intersections and minor arterial roads are associated with an increase in crash risk, while the presence of on street cycle lanes, local roads and residential, conservation and open space planning zones can be associated with a decrease in crash probability. 


\section{References}

Aertsens, J., de Geus, B., Vandenbulcke, G., Degraeuwe, B., Broekx, S., De Nocker, L., Liekens, I., Mayeres, I., Meeusen, R., Thomas, I., Torfs, R., Willems, H., \& Int Panis, L. (2010). Commuting by bike in Belgium, the costs of minor accidents. Accident Analysis and Prevention, 42(6), 21492157. doi.org/10.1016/j.aap.2010.07.008

Aultman-Hall, L., \& Kaltenecker, M. G. (1999). Toronto bicycle commuter safety rates. Accident Analysis and Prevention, 31(6), 675-686. doi.org/10.1016/S0001-4575(99)00028-7

Bertolini, L., \& le Clercq, F. (2003). Urban development without more mobility by car? Lessons from Amsterdam, a multimodal urban region. Environment and Planning A, 2003(35), 575-589. doi. org/10.1068/a3592

Bíl, M., Bílová, M., \& Müller, I. (2010). Critical factors in fatal collisions of adult cyclists with automobiles. Accident Analysis and Prevention, 42(6), 1632-1636. doi.org/10.1016/j.aap.2010.04.001

Chimba, D., Emaasit, D., \& Kutela, B. (2012). Likelihood parameterization of bicycle crash injury severities. Journal of Transportation Technologies, 2012(2), 213-219. doi.org/10.4236/jtts.2012.23023

Christchurch City Council. (2016). Christchurch city plan. Retrieved from https:/cityplan.ccc.govt. nz/pages/plan/book.aspx

Christchurch City Council. (2012). Road level classification list. Retrieved from http://resources.ccc. govt.nz/files/roadlevelclassificationlist.pdf

Christchurch City Council. (2011). Posted speed limits. Christchurch, New Zealand.

Christchurch City Council. (2008). 2008 cycling map [hard copy]. Christchurch, New Zealand.

Christchurch City Council. (n.d.). Proposed district plan: Appendix 7.12. Retrieved from http://www. proposeddistrictplan.ccc.govt.nz/common/user/contentlink.aspx?HID=24754

Cycling Safety Panel. (2014). Safer journeys for people who cycle: Cycling safety panel final report and recommendations. Retrieved from http://www.saferjourneys.govt.nz/assets/Safer-journeys-files/ Cycling-safety-panel-final-report.pdf

City of Copenhagen. (2009). Economic evaluation of cycle projects—methodology and unit prices. Copenhagen: City of Copenhagen.

de Geus, B., Vandenbulcke, G., Int Panis, L., Thomas, I., Degraeuwe, B., Cumps, E., Aertsens, J., Torfs, R., \& Meeusen, R. (2012). A prospective cohort study on minor accidents involving commuter cyclists in Belgium. Accident Analysis and Prevention, 45, 683-693. doi.org/10.1016/j.aap.2011.09.045

Dill, J., \& McNeil, N. (2014). Four types of cyclists? Examination of typology for better understanding of bicycling behavior and potential. Transportation Research Record: Journal of the Transportation Research Board, 2387(1), 129-138. doi.org/10.3141/2387-15

Eckhardt, N., \& Thomas, I. (2005). Spatial nested scales for road accidents in the periphery of Brussels. IATSS Research 29(1), 66-78. doi.org/10.1016/S0386-1112(14)60120-5

Elvik, R. (2008). The non-linearity of risk and the promotion of environmentally sustainable transport. Accident Analysis and Prevention, 41, 849-855.

Ewing, R., Meakins, G., Hamidi, S., \& Nelson, A. C. (2014). Relationship between urban sprawl and physical activity, obesity, and morbidity-Update and refinement. Health and Place, 26, 11-126. doi.org/10.1016/j.healthplace.2013.12.008

Frumkin, H., Frank, L. D., \& Jackson R. B. (2004). Urban sprawl and public health: Designing, planning, and building for healthy communities. Washington, DC: Island Press.

Grimes, D., \& Schulz, K. (2005). Compared to what? Finding controls for case-control studies. The Lancet, 365, 1429-1433.

Hels, T., \& Orozova-Bekkevold, I. (2007). The effect of roundabout design features on cyclist crash rate. 
Accident Analysis and Prevention, 39(2), 300-307. doi.org/10.1016/j.aap.2006.07.008

Herslund, M., \& Jorgensen, N. (2003). Looked-but-failed-to-see-errors in traffic. Accident Analysis and Prevention, 35(6), 885-891. doi.org/10.1016/S0001-4575(02)00095-7

Jacobsen, P. (2003). Safety in numbers: More walkers and bicyclists, safer walking and bicycling. Injury Prevention, 9(3), 205-209. doi.org/10.1136/ip.9.3.205

Isaksson-Hellman, I. (2012). A study of bicycle and passenger car collisions based on insurance claims data. Annals of Advances in Automotive Medicine/Annual Scientific Conference, 56, 3-12.

Kim, J.-K., Kim, S., Ulfarsson, G. F., \& Porrello, L. A. (2007). Bicyclist injury severities in bicyclemotor vehicle accidents. Accident Analysis and Prevention, 39(2), 238-251. doi.org/10.1016/j. aap.2006.07.002

Koh, P. P., \& Wong, Y. D. (2013). Influence of infrastructural compatibility factors on walking and cycling route choice. Journal of Environmental Psychology, 36(2013), 202-213. doi.org/10.1016./j. jenvp.2013.08.001

Kuzmyak, R. (2012). Land use and traffic congestion. Federal Highway Administration Report, FHWA-AZ-12-618. Retrieved from https:/www.azdot.gov/docs/default-source/planning/az618. pdf?sfvrsn $=2$

Li, L., Zhu, L.,\& Sui, D. Z. (2007). A GIS-based Bayesian approach for analyzing spatial-temporal patterns of intra-city motor vehicle crashes. Journal of Transport Geography, 15(4), 274-285. doi. org/10.1016/j.jtrangeo.2006.08.005

Land Information New Zealand [LINZ]. (2011). New Zealand street address (electoral) points. Retrieved from https://data.linz.govt.nz/layer/779-nz-street-address-electoral

Loo, B. P., \& Tsui, K. L. (2010). Bicycle crash casualties in a highly motorized city. Accident Analysis and Prevention, 42(6), 1902-1907. doi.org/10.1016/j.aap.2010.05.011

Lord, D., \& Mannering, F. (2010). The statistical analysis of crash-frequency data: A review and assessment of methodological alternatives. Transportation Research Part A: Policy and Practice, 44(5), 291-305. doi.org/10.1016/j.tra.2010.02.001

Loidl, M., Wallentin., G., Wendel., R., \& Zagel, B. (2016). Mapping bicycle crash risk patterns on the local scale. Safety 2(3) 17. doi:10.3390/safety2030017

Ministry of Transport [MOT]. (2014). Cyclists: 2014. Retrieved from http://www.transport.govt.nz/ assets/Uploads/Research/Documents/Cycling-2014.pdf

Nielsen, T. A. S., Olafsson, A. S., Carstensen, T. A., \& Skov-Petersen, H. (2013). Environmental correlates of cycling: Evaluating urban form and location effects based on Danish micro-data. Transportation Research Part D: Transport and Environment, 22, 40-44. doi.org/10.1016/j.trd.2013.02.017

New Zealand Transport Agency. (2014a). Crash data for all of New Zealand 2000 onwards. Retrieved from http://www.nzta.govt.nz/resources/crash-analysis-system-data/index.html

New Zealand Transport Agency. (2014b). Guide for the interpretation of coded crash reports from the Crash Analysis System (CAS). Retrieved from http://www.nzta.govt.nz/assets/resources/guide-tocoded-crash-reports/docs/guide-to-coded-crash-reports.pdf

Organization for Economic Co-operation and Development [OECD]. (2013). Cycling, health and safety. Paris: ITF-OECD Working Group on Cycling Safety.

Parsons, J., \& Koorey, G. (2013). The effect of cycle lanes on cycle numbers and safety. Proceedings from the IPENZ Transportation Group Conference, Dunedin, New Zealand, April 2013. Retrieved from http://conf.hardingconsultants.co.nz/workspace/uploads/koorey-glen-ipenztg2013-t5191b73135b7e.pdf

Parkin, J., \& Meyers, C. (2010). The effect of cycle lanes on the proximity between motor traffic and cycle traffic. Accident Analysis and Prevention, 42(1), 159-165. doi.org/10.1016/j.aap.2009.07.018 
Pucher, J., \& Buehler., R. (2008). Making cycling irresistible: Lessons from the Netherlands, Denmark and Germany. Transport Reviews, 37(6), 495-528. doi.org/10.1080/01441640701806612

Rabl, A., \& de Nazelle, A. (2012). Benefits of shift from car to active transport. Transport Policy, 19(1), 121-131. doi.org/10.1016/j.tranpol.2011.09.008

Räsänen, M., \& Summala, H. (1998). Attention and expectation problems in bicycle-car collisions: An in-depth study. Accident Analysis \& Prevention, 30(5), 657-666. doi.org/10.1016/S00014575(98)00007-4

Reyonlds, C. C., Harris, A. M., Teschke, K., Cription, P. A., \& Winters, M. (2009). The impact of transportation infrastructure on bicycling injuries and crashes: A review of the literature. Environmental Health, 8, 47. Retrieved from http://www.ehjournal.net/content/8/1/47

Rietveld, P., \& Daniel, V. (2004). Determinants of bicycle use: Do municipal policies matter? Transportation Research Part A: Policy and Practice, 38(7), 531-550. doi.org/10.1016/j.tra.2004.05.003

Roberts, P. (2012) Christchurch strategic cycle model. Christchurch, New Zealand: Quality Transport Planning.

Roberts, P. J. (2014). Cycle demand-planning for tomorrow. 2 Walk 2 Cycle National Conference, Nelson, New Zealand. Retrieved from https://www.researchgate.net/profile/Paul_Roberts32/publication/303858672_CYCLE_DEMANDPLANNING_FOR_TOMORROW/ links/5758cfde08aed88462068124/CYCLE-DEMAND-PLANNING-FOR-TOMORROW.pdf

Schepers, J. P., Heinen, E., Methorst, P., \& Wegman, F. (2013b). Road safety and bicycle usage impacts of unbundling vehicular and cycle traffic in Dutch urban networks. European Journal of Transport and Infrastructure Research, 13(3), 221-238. Retrieved from https://www.ejtir.tbm.tudelft.nl

Schepers, J. P., Hagenzieker, M., Methorst, R., van Wee, B., \& Wegman, F. (2013a). A conceptual framework for road safety and mobility applied to cycling safety. Accident Analysis and Prevention, 62, 331-340. doi.org/10.1016/j.aap.2013.03.032

Schepers, J. P., Kroeze, P. A., Sweers, W., and Wüst, J. C. (2011). Road factors and bicycle-motor vehicle crashes at unsignalized priority intersections. Accident Analysis and Prevention, 43(3), 853-861. doi. org/10.1016/j.aap.2010.11.005

Statistics New Zealand. (2013). Commuting patterns in greater Christchurch: Trends from the Census of Population and Dwellings 2006 and 2013. Retrieved from http://www.stats.govt.nz/Census/2013census/profile-and-summaryreports/commutingpatternschch/Commuting_and_modes_of_transpo.aspx\#car

Stewart, K., \& McHale, A. (2014). Cycle Lanes: Their effect on driver distances in urban areas. Transport 29(3), 307-316. doi.org/10.3846/16484142.2014.953205

Teschke, K., Harris, M. A., Reynolds, C. C., Winters, M., Babul, S., Chipman, M., Cusimano, M. D., Brubacher, J. R., Hunte, G., Friedman, S. M., Monro, M., Shen, H., Vernich, L., \& Cripton, P. A. (2012). Route infrastructure and the risk of injuries to bicyclists: A case-crossover study. American Journal of Public Health, 102(12), 2336-2343. doi.org/10.2105/AJPH.2012.300762.

Transport for London (2017) Cynemon - cycling network model for London, presentation by Aled Davies to Cycling@Teatime, March 2017. https://www.ucl.ac.uk/transport-institute/pdfs/Davies_ slides

Vandenbulcke, G., Dujardin, C., Thomas, I., de Geus, B., Degraeuwe, B., Meeusen, M., \& Int Panis, L., (2011). Cycle commuting in Belgium: Spatial determinants and 're-cycling' strategies. Transportation Research Part A, 45, 118-137 doi.org/10.1016/j.tra.2010.11.004

Vandenbulcke, G., Thomas, I., \& Int Panis, L. (2014). Predicting cycling crash risk in Brussels: A spatial case-control approach. Accident Analysis and Prevention, 62, 341-357. doi.org/10.1016/j. aap.2013.07.001 
Wiersma, J., Bertolini, L., \& Straatemeier, T. (2016). How does the spatial context shape conditions for car dependency? An analysis of the differences between and within regions in the Netherlands. Journal of Transport and Land Use, 9(3), 35-55. Retrieved from https://www.jtlu.org/index.php/jtlu/ article/viewFile/583/812

Wang, Y., \& Nihan, N. L. (2004). Estimating the risk of collisions between bicycles and motor vehicles at signalized intersections. Accident Analysis and Prevention, 36(3), 313-321. doi.org/10.1016/ S0001-4575(03)00009-5

Wallentin, G., \& Loidl, M. (2015). Agent-based bicycle traffic model for Salzburg city. GI_Forum Journal for Geographic Information Science, 1, 558-566 doi.org/10.1553/giscience2015s558

Wallentin, G., and Loidl, M. (2016). Bicycle-bicycle accidents emerge from encounters: An agent-based approach. Safety, 2(2) 14. doi.org/10.3390/safety2020014

Wegman, F., Zhang, F., \& Dijkstra, A. (2012). How to make more cycling good for road safety? Accident Analysis and Prevention, 44(1), 19-29. doi.org/10.1016/j.aap.20

Ziemeke, D., Metzler, S., \& Nagel, K. (2017). Modelling bicycle traffic in an agent-based simulation. Procedia, 109C, 923-928. doi.org/10.1016/j.procs.2017.05.424 